\title{
A escravidão contemporânea no Brasil e a perda da propriedade privada
}

\section{- La esclavitud contemporánea en Brasil y la pérdida de la propiedad privada}

\section{- Contemporary slavery in Brazil and the loss of private property}

O Brasil, último país a acabar com a escravidão, tem uma perversidade intrínseca na sua herança,

que torna a nossa classe dominante enferma de desigualdade e de descaso.

Darcy Ribeiro

\section{Pedro Greco Teixeira Pinos Greco ${ }^{1}$ \\ Ricardo Rezende Figueira ${ }^{2}$}

Resumo: Esse ensaio deseja se debruçar sobre uma discussão do papel da legislação na erradicação da escravidão contemporânea. Um dos temas prementes é o da perda da propriedade privada daquele que incorre no crime previsto no art. 149 do Código Penal (CP) e na conduta prevista no art. 243 da Constituição. Como pano de fundo há certamente questões políticas, econômicas, sociais e jurídicas que circunscrevem esse assunto. Por trás desse dispositivo constitucional, houve um longo debate para a aprovação da Emenda Constitucional no 81 de 2014. Desse modo, desejaremos fazer uma revisão

1 Mestrando em Direitos Humanos e Políticas Públicas pelo NEPP-DH/UFRJ. Professor de Direito Civil da Faculdade Gama e Souza. pedrotpgreco@gmail.com

2 Graduado em Filosofia, mestrado em Ciências Sociais, e doutorado no Programa de Pós-Graduação em Ciências umanas, pela UFRJ e pós doutorado na Universidad Carlos III, de Madrid. É docente na UFRJ. rrfiguei@uol.com.br 
dessa temática para que reforcemos o efeito emancipatório dos direitos humanos na luta antiescravista com o objetivo de melhor vislumbrarmos alguns dos motivos pelo qual pouco prospera a pauta que prevê a perda da propriedade privada em casos de escravidão contemporânea no Brasil. No que diz respeito aos referenciais teóricos utilizaremos como base Joaquin Herrera Flores e David Sánchez Rubio por serem autores de escol no estudo dos Direitos Humanos.

Palavras-chave: Escravidão contemporânea. Perda da propriedade privada.

Resumen: Este ensayo tiene como objetivo abordar una discusión sobre el papel de la legislación en la erradicación de la esclavitud contemporánea. Uno de los temas urgentes es la pérdida de la propiedad privada de quienes incurren en el delito previsto en el art. 149 del Código Penal (CP) y en la conducta prevista en el art. 243 de la Constitución. En el trasfondo ciertamente hay cuestiones políticas, económicas, sociales y legales en torno a este tema. Detrás de esta disposición constitucional, hubo un largo debate para la aprobación de la Enmienda Constitucional No. 81 de 2014. Así, vamos a querer revisar este tema para que podamos reforzar el efecto emancipador de los derechos humanos en la lucha contra la esclavitud con el fin de para vislumbrar mejor algunas de las razones por las que la agenda que prevé la pérdida de la propiedad privada en los casos de esclavitud contemporánea en Brasil no prospera. En cuanto a las referencias teóricas, usaremos a Joaquín Herrera Flores y David Sánchez Rubio como base para ser autores destacados en el estudio de los Derechos Humanos.

Palabras clave: Esclavitud contemporánea. Pérdida de propiedad privada.

Abstract: This essay aims to discuss the role of legislation in the eradication of contemporary slavery. One of the urgent issues is the loss of the private property of those who commit the crime provided for in art. 149 of the Penal Code (CP) and in the conduct provided for in art. 243 of the Constitution. In the background, there are certainly political, economic, social and legal issues surrounding this issue. Behind this constitutional provision, there was a long debate for the approval of Constitutional Amendment No. 81 of 2014. Thus, we will want to review this issue so that we can reinforce the emancipatory effect of human rights in the fight against slavery in order to have a better glimpse some of the reasons why the agenda that foresees the loss of private 
property in cases of contemporary slavery in Brazil does not prosper. As for the theoretical framework, we will use Joaquín Herrera Flores and David Sánchez Rubio as a basis for being prominent authors in the study of Human Rights.

Keywords: Contemporary slavery. Loss of private proprety.

\section{Introdução}

O objetivo desse estudo é examinar a perda de propriedade privada, em respeito à Emenda Constitucional no 81 de 2014 que reformou o art. 243 da Constituição de 1988. Em paralelo vamos comentar sobre o papel do Congresso Nacional na elaboração dessa futura lei que regulamentará a aplicação desse dispositivo constitucional. Ainda vamos aventar o porquê do Legislativo, na prática, esvaziar essa ferramenta de enfrentamento ao crime de escravidão contemporânea.

Em giro próximo, para compreender o que se passa no enfrentamento ao crime de escravidão contemporânea, faz-se relevante o exame do art. 149 do $\mathrm{CP}$ e de outros instrumentos infralegais como a portaria $\mathrm{n}^{\circ} 1.129$ de 2017 do Ministério do Trabalho e Emprego, de decisões jurisdicionais nacionais e internacionais e das convenções internacionais sobre essa temática.

No que tange a metodologia, o escrito compreende a análise doutrinária, social, legislativa e documental, desejando que seja feito um tratamento analítico-interpretativo e, igualmente, será conduzida uma pesquisa bibliográfica relendo esses temas. Deseja-se tratar o assunto com um olhar interdisciplinar para que as diferentes áreas das ciências humanas e sociais se complementem enriquecendo o conhecimento produzido, consoante à obra de Joaquin Herrera Flores (2008, p. 21).

Ao mesmo tempo, em uma perspectiva emancipatória dos direitos humanos, tendo em mente o trabalho de David Sánchez Rubio (2014, p. 18). Com outra perspectiva teórica citaremos Norberto Bobbio $(2004$, p. 79$)$ que reconhece não existirem direitos absolutos ${ }^{3}$, salvo o de não ser escravizado ou torturado.

Assim, indicamos o inteiro teor do novo dispositivo constitucional para que o vejamos, em detalhes, sendo que em outras partes do texto refletiremos mais minudenciaras em relação à Emenda à Constituição no 81/20144.

3 Os direitos absolutos seriam aqueles que não podem ser confrontados, ou seja, seriam eles inquestionáveis, sem exceção ou sem discussão, como prevêem os sistemas Europeu e Interamericano de Direitos Humanos.

4 As propriedades rurais e urbanas de qualquer região do País onde forem localizadas culturas ilegais de plantas psicotrópicas ou a exploração de trabalho escravo na forma da lei serão expropriadas e destinadas à reforma agrária e a programas de habitação popular, sem qualquer indenização ao proprietário e sem prejuízo de outras sanções 
Percebemos que o crime de escravidão contemporânea atenta contra a dignidade humana, por meio de ações contra a liberdade, a integridade física, a baixa ou nenhuma remuneração pelo trabalho desenvolvido, a exaustão ou degradância nas atividades de labor, os encargos trabalhistas e previdenciários sonegados e as condições estruturais pertinentes para o exercício digno do trabalho.

Como demonstração do problema, em 2020, houve o resgate de $^{5} 2$ pessoas, sendo que a pandemia de COVID-19 paralisou parcialmente as atividades de fiscalização pelas dificuldades de deslocamento - havia a orientação de não se utilizar aviões nas viagens: pela idade ou por doença (comorbidades) de alguns auditores do trabalho, pelo atraso na vacinação, pela escassez de recursos econômicos para os deslocamentos, sem contar com a extinção do Ministério do Trabalho e Emprego que desmobilizou em parte essa pauta. Não fosse isso, talvez o número de resgatados fosse maior.

Quanto ao plano internacional, é preciso pensar em movimentos abolicionistas crescentes desde o século XVIII. Vários tratados têm reiterado a proibição da escravidão, como, em 1926, a Liga das Nações, em Genebra, definiu a Convenção sobre a escravatura; em 1948, a Organização das Nações Unidas (ONU) proclamou no art. $4^{\circ}$ da Declaração Universal dos Direitos Humanos que ninguém seria mantido em escravidão ou servidão e que o tráfico de pessoas para a escravidão seria proibido em todas as formas; em 1956, foi adotado em Genebra, um protocolo de Convenção Suplementar sobre a Abolição da Escravatura do Tráfico de Escravos e das Instituições e Práticas Análogas à Escravatura.

Essa legislação nacional e internacional e os sistemas regionais de Direitos Humanos europeu, interamericano e africano demonstram que o problema não está solucionado nem no Brasil nem no mundo. De fato, ao longo do século XX, alguns países admitiam legalmente a escravização de pessoas, como o Marrocos que só aboliu em 1956, a Arábia Saudita, em 1962, e a Mauritânia, em 1981.

Sabemos que o mundo não é o reflexo apenas dos atos normativos. A realidade é mais complexa, a construção de valores se expressa em declarações, constituições e legislações que revelam mais que o mundo do "ser", o do "dever ser" e há um espaço enorme entre a idealização da Constituição, da positivação da lei e da sua execução. Por isso, o tema trazido aqui é atual e exige medidas jurídicas, mas também ações políticas preventivas, curativas e estruturais.

E sublinhamos que o direito se dá e se transforma no curso da história hu-

previstas em lei, observado, no que couber, o disposto no art. $5^{\circ}$. (artigo 243 Constituição Federal) Parágrafo único. Todo e qualquer bem de valor econômico apreendido em decorrência do tráfico ilícito de entorpecentes e drogas afins e da exploração de trabalho escravo será confiscado e reverterá a fundo especial com destinação específica, na forma da lei. (Grifos nossos)

5 Disponível em: https://noticias.uol.com.br/colunas/leonardo-sakamoto/2021/01/27/brasil-resgata-942-pessoas-do-trabalho-escravo-no-primeiro-ano-da-covid-19.htm. Acesso em: 11 mai. 2021. 
mana, deveria haver uma interpretação evolutiva e de proteção da pessoa humana, sobretudo, daquelas em situação de maior vulnerabilidade social e que estivessem expostas à escravidão contemporânea.

\section{Escravidão contemporânea no Brasil: (falsos) avanços e (verdadeiros) retrocessos?}

Apesar de termos leis em nosso país e tratados da comunidade internacional, o problema persiste aqui e em outras regiões do globo. Com isso, faremos algumas provocações:

Será que as regras brasileiras, a saber: o art. 149 do CP e o art. 243 da Constituição, não são suficientemente claras? Falta, no caso brasileiro, a segurança nas relações sócio-jurídicas trabalhistas? Carecemos de um conceito mais firme, embora maleável, de escravidão contemporânea, dentro do art. 149 do CP e do art. 243 da Constituição? Será que estamos permitindo ao julgador administrativo e/ou judicial uma desproporcional margem de discricionariedade? Será que temos todos esses problemas juntos?

São muitas as indagações, sendo que não é nosso objetivo sanear todas essas questões. De fato, há controvérsia entre os especialistas, por questões que podem ser além de técnicas, políticas e ideológicas. Na doutrina, por exemplo, Lívia Mendes Moreira Miraglia (2008, p. 135) reafirma o texto da lei:

é aquele que se realiza mediante a redução do trabalhador a simples objeto de lucro do empregador. O obreiro é subjugado, humilhado e submetido a condições degradantes de trabalho e, em regra, embora não seja elemento essencial do tipo, sem o direito de rescindir o contrato ou de deixar o local de labor a qualquer tempo.

Nesse mesmo esquadro, Rebecca Scott (2013, p. 1-2) contribui com a nossa discussão:

Os que se opõem à criminalização da exploração do trabalho escravo, e à expropriação de propriedades em que o uso de trabalho escravo for confirmado, usam o argumento de que a definição legal de uma situação de escravidão não é clara e que as medidas previstas pela Proposta de Emenda Constitucional atualmente em debate no Senado abririam a possibilidade de abusos por parte de fiscais ou procuradores. Assim, em vez de examinar os parâmetros bem concretos usados por procuradores e fiscais que atuam nessa área, preferem apenas sugerir que a definição de "trabalho escravo" ainda é bastante abstrata e controvertida. [...]

Sabemos todos que esses argumentos são frequentemente movidos pela má fé e pelo desejo de lucro. Para fazer frente a esses problemas e questionamentos, no entanto, é importante que juristas e outras pessoas que lidam com essa temática levem a sério a questão da definição. Este artigo propõe uma contribuição histórica para esse esforço de esclarecimento. Como definir "escravidão" ou "tra- 
balho escravo"? O que fazia de alguém um escravo no século XIX, quando a escravidão era uma instituição reconhecida e identificada com a propriedade sobre as pessoas?

Desse embate entre forças antagônicas, vemos que a polarização desaguou na portaria no 1.129 de 2017 do Ministério do Trabalho e Emprego que restringiu a categoria à submissão do trabalhador e à ameaça de punição por meio de coação e ao impedimento do ir e vir. Importa assinalar, de forma ligeira, que nessa primeira portaria o Executivo federal demonstrava, pela sua redação fria, desconhecer o texto do art. 149 do CP e a literalidade do art. 243 da CR.

Além disso, inventou nova definição de escravidão contemporânea que afrontava as normas pátrias e acaba defendendo o interesse dos escravizadores. Em tese comungada também por Daniel de Souza Trindade (2014, p. 38) vemos críticas em relação à flexibilização do conceito de escravidão contemporânea:

\begin{abstract}
Muito se avançou no enfrentamento ao trabalho escravo no Brasil. Parte desse avanço, como foi dito, é devida à alteração legislativa que ampliou o conceito do crime, permitindo a punição nos casos em que forem flagrantes as condições degradantes ou a imposição de jornada exaustiva. Registra-se que essas modalidades de exploração hoje representam a maior expressividade em relação aos resgates do trabalho escravo, superando casos de restrição de liberdade ou servidão por dívidas, por exemplo.

Retirar tais elementos do atual conceito brasileiro de trabalho escravo, como propõem alguns, significa reduzir (em muito) o alcance das fiscalizações e, em consequência, diminuir a eficácia na proteção ao trabalhador. Mais ainda, importa na mitigação do princípio da dignidade da pessoa humana, principal objeto tutelado pela norma penal em comento. (Grifo nosso).
\end{abstract}

Essa portaria, após ser contestada por vários autores (Nelson; Teixeira; Nelson, 2018, p. 13), foi suspensa pela Ministra Rosa Weber por meio da Medida Cautelar na Arguição de Descumprimento de Preceito Fundamental no 489/DF, em julgamento que ocorreu em 23 de outubro de 2017 e, após pressões, o executivo federal a substituiu pela portaria no 1.293 de 2017, do Ministério do Trabalho e Emprego.

O equívoco da primeira portaria ${ }^{6}$ reside nos obstáculos criados para o reconhecimento da categoria escravidão. Apesar do art. 149 do CP não restringir o conceito à privação da liberdade ou a coerção, a portaria no 1.129 de 2017 reduziu o conceito aos casos de isolamento geográfico e/ou a coação pela vigilância ostensiva, além das restrições ligadas à liberdade de ir e vir da pessoa.

Em outras palavras, traiu o texto da lei e talvez revelasse um imaginá-

6 Essas duas portarias foram produto do governo Michel Temer que estava afinado com uma pauta liberal e ao mesmo tempo, pouco atento ao ementário social de proteção das pessoas em situação de vulnerabilidade, notadamente, as pessoas escravizadas. 
rio de uma escravização pré-Lei Áurea de 1888, que atendia aos escravizadores do século XXI, não ao texto legal, e tampouco aos escravizados.

Ademais, essa primeira portaria está incongruente com a jurisprudência do Supremo Tribunal Federal exposta no Inquérito no 3.412/AL de relatoria do Ministro Marco Aurélio e relatoria para o acórdão da Ministra Rosa Weber, em julgamento que ocorreu no dia 29/03/2012, e que foi publicado no DJe no dia $12 / 11 / 2012$, em que vemos com clareza essa ideia de que nos tempos presentes temos uma fardagem de que a escravidão contemporânea precisa ser bloqueada com as ferramentas do terceiro milênio e não com as armas do pretérito.

Nesse mesmo passo, a Corte Interamericana de Direitos Humanos (CIDH), no notório caso 'Trabalhadores da Fazenda Brasil Verde', condenou o nosso país por não proteger trabalhadores em situação de escravidão contemporânea. Nesse julgado paradigmático, o Brasil foi obrigado a reabrir as investigações penais para que sejam identificados, processados e punidos os escravizadores, bem como indenizar as vítimas em caso examinado por Ricardo Rezende Figueira (2017, p. 33-36).

O impedimento ao direito de ir e vir não é mais uma regra, como aparentemente se imagina que era no passado. Exemplo disso são os escravos de ganho no século XIX, que seja no Rio de Janeiro ou em Buenos Aires, muitas vezes sequer moravam com seus senhores. Transitavam no decorrer do dia trabalhando ou buscando trabalho pelas ruas e no final do dia levavam a diária ao seu proprietário. Com esse mesmo teor crítico, mesmo antes da promulgação da mudança no artigo 149, Ela Wiecko V. de Castilho (2000, p. 57) nos mostra que:

\begin{abstract}
A conduta de escravizar não se limita à violação da liberdade física e pode existir mesmo havendo liberdade de locomoção. A vítima é livre do ponto de vista físico para deixar o trabalho, mas não o deixa porque se sente escravo. A escravidão se estabelece de forma sutil e complexa com a participação de vários agentes e até com o consentimento da vítima. Ficam próximos, às vezes se superpõem, os conceitos de trabalho escravo, de trabalho degradante e trabalho em condições indignas e subumanas, pois o estado de escravo implica negar a dignidade humana (status dignitatis).
\end{abstract}

Em verdade, a portaria no 1.129 de 2017 rompia com a norma princípio da vedação ao retrocesso aos direitos humanos sócio-laboral, que é uma das pedras de toque do direito nacional e internacional. A norma-princípio da vedação ao retrocesso em uma leitura à luz das relações trabalhistas revela forte similitude entre os direitos fundamentais e os laborais.

Conforme José Joaquim Gomes Canotilho (1998, p. 321) ao tratar da legítima expectativa da sociedade e dos indivíduos de serem credores de direitos humanos ofertados pelo Estado, e de não terem seus direitos diminuídos ou abalados. Devemos sempre caminhar para frente, conquistar mais e 
melhores direitos e nesse tema da escravidão contemporânea isso não só é uma necessidade, é uma premência.

Nesse mesmo exame principiológico, para dar um encaminhamento tangível a esse assunto, sustentamos que devemos empunhar também as normas-princípio da proteção social do trabalhador (pro personae), in dubio pro misero e da norma mais favorável ao trabalhador, vigas mestras do Direito do Trabalho, que poderiam auxiliar os intérpretes na correta hermenêutica dessa matéria.

Com isso a ideia é que ao cumularmos essas normas-princípio, desemboquemos na legislação que seja o mais protetiva ao trabalhador, e que garanta mais direitos e que tudo isso não retroceda. Contra involuções, Lília Carvalho Finelli (2016, p. 177) evidencia a importância dessa norma-princípio aplicada ao combate à escravidão contemporânea:

\begin{abstract}
Os ataques ao art. 149 do Código Penal são frequentes e mostram desconhecimento sobre a evolução da proteção ao trabalhador. Por isso, de sua análise não poderia resultar outra conclusão que a de afronta ao princípio da vedação ao retrocesso. Ao progredir no tratamento da questão, exatamente como determinam as normas internacionais assinadas, o país não tem como possibilidade regredir ao conceito de que apenas seria conduta criminosa a restrição da liberdade.
\end{abstract}

Por essa razão quanto à escravidão contemporânea, em si, concebemos que duas excelentes diretrizes estão gravitando em torno do bom art. 149 do CP e da icônica decisão da Corte Interamericana e assim nesse fragmento citado da $\mathrm{CIDH}$, que é emblemático, vemos a mazela que a escravidão contemporânea proporciona, nos nossos tempos.

Desse jeito, uma portaria deve ser afastada para que os administradores do Estado brasileiro se norteiem por esse dispositivo do CP e o precedente judicial internacional que possui força vinculante a comunidade interamericana que reconhece a competência da Corte. Sobre o conteúdo jurisdicional dessa contundente sentença Carlos Henrique Borlido Haddad e Lívia Mendes Moreira Miraglia (2018, p. 118) nos revelam a seguinte fala:

\begin{abstract}
O Caso Brasil Verde vem sendo considerado por esses representantes como um importante marco para afirmação do conceito brasileiro, acreditando-se que, em razão de todo o histórico de julgamentos da Corte, da sua função de garantidora dos direitos humanos e levando-se em consideração o desfecho do caso José Pereira, a decisão proferida nesse caso representará um avanço real no sentido da erradicação definitiva dessa chaga que ainda assola o nosso país.
\end{abstract}

Por tudo que foi ostentado até aqui, notamos que existe método, a nosso parecer, em nossa política antiescravista; isto significa, que a primeira portaria de 2017 não foi feita por acaso, dado que ela se insere em uma fotografia maior em que existe uma estratégia de drenagem da luta antiescravista 
e isso passa por leis, atos infralegais, políticas públicas e outras táticas para tentar escoar o conteúdo da mais recente novidade introduzida na Constituição pela EC no 81 de 2014 que é a perda da propriedade privada por aquele que usa a escravidão contemporânea.

Em epítome, a escravidão contemporânea é um assunto complexo e que tem na ponta pessoas escravizadas que estão, em regra, em pungente situação de vulnerabilidade laboral e social e assim deveriam receber um tratamento especial de abrigo, consoante às normativas brasileiras e internacionais, tudo consoante aos direitos humanos emancipatórios.

\section{Por que a perda da propriedade privada pela escravi- dão contemporânea não avança?}

Com esse substrato mínimo alinhado e com algumas discussões relevantes já acostadas, podemos fazer uma análise da escravidão contemporânea que esteja em simetria com algumas questões sociais, políticas, culturais, jurídicas e econômicas do Brasil. Desse modo, evoluímos para uma parte de nossos apontamentos que envolverá o acesso à terra, a eventual resposta pouco agressiva do Brasil contra a escravidão contemporânea no que tange ao uso da propriedade privada e como ocorreu a positivação na Constituição brasileira desse instituto que deseja retirar a propriedade privada (rural ou urbana) daquele que abuse do seu direito se valendo do crime.

Desse jeito, iniciamos esse item, de forma propriamente dita, vendo que a propriedade privada de um bem imóvel é tanto um direito quanto uma responsabilidade, porquanto o seu proprietário deve encarregar-se de uma série de obrigações que passam pelo pagamento do respectivo tributo, observância das normas civis-ambientais, como por exemplo, não desmatar acima de determinado porcentagem como determina o Código Florestal (Lei $n^{\circ}$ 12.651/2012) ou estar em dias com seus encargos pecuniários perante o seu respectivo condomínio ou também a impossibilidade de ofensa às relações trabalhistas o que inclui todo o espectro laboral, incluindo a vedação ao uso da escravidão contemporânea.

Assim, nunca é demasiado pontuar que o tripé da função social da propriedade (tributário, civil-ambiental-administrativo e penal-trabalhista) não é novo, porque está listado nos incisos do art. 186 da Constituição da República que trata da função social da propriedade no meio rural, sendo a redação original de 1988.

Por isso deve-se bater palmas para a função social da propriedade dentro da Constituição, porém, perguntamos quais ações concretas fizemos para que essa função social seja cumprida na práxis, em especial, quando cru- 
zamos esse assunto com a necessária defesa dos trabalhadores em situação de escravidão contemporânea?

Contudo, não se desconhece que o problema não é somente a portaria ou a falta de texto da lei, detalhando o art. 243 da Constituição. O desafio é muito mais profundo e denso e envolve o setor político, social, cultural, econômico e jurídico, sendo que nesse texto tentamos justamente mostrar a gravidade dessa moldura.

Pelo exposto, vale consagrar que a propriedade privada que se vale da escravidão contemporânea viola de morte a sua função social e por isso a perda da propriedade garantiria um incremento substancial na reforma agrária e nos programas de habitação popular. Nisso podemos dizer que temos uma dívida histórica com a reforma agrária e as habitações populares que nunca foram seriamente saldadas desde a independência do Brasil.

Infortunadamente, não podemos relacionar como iniciativa digna de nota a veloz elaboração da lei que permite a perda da propriedade privada pela escravidão contemporânea, por outra forma, somos pródigos em legiferar e mudar a Constituição, porém, não atentamos para o fato de que o mundo social não se revoluciona em um passe de mágica, sem medidas efetivas que sejam vigorosas em solucionar ou pelo menos suavizar problemas estruturais.

Isto posto, precisamos sair do mundo das ideias e adentrar as trincheiras sociais com o intuito de resolver a mazela da escravidão contemporânea e ungir a política pública prioritária a perda da propriedade privada do escravizador. Certamente, essa via será bastante prestigiosa para rever essa agenda social que é teórica e nem sempre prática.

Na seara política precisamos dizer que existe uma tradição na história brasileira de enquadrar a propriedade privada como sacrossanta, sendo uma das espinhas dorsais da sociedade capitalista e que no Brasil tem um evoluir de muita desigualdade social em que as terras (urbanas e rurais) estão majoritariamente concentradas nas mãos de poucas pessoas.

Desse jeito, ideias como essa de melhor distribuição de propriedades (supostamente) geraria instabilidade social, fenômeno esse que seria, em teoria, um atentado contra a materialização do capital, bem como uma iniciativa que beiraria o socialismo/comunismo.

De qualquer forma, como afirmou Ricardo Rezende Figueira (2018, p. 117) o problema da pobreza, da desigualdade de renda, da propriedade privada e da escravidão contemporânea estão emaranhadas:

Qual a razão da persistência deste crime, se são implementadas tantas medidas? O problema é complexo e exige decisões que encontram fortes resistências. Sem tocar profundamente na distribuição de renda, sem gerar empregos e superar os bolsões de miséria e desemprego, sem oferecer uma educação pública de boa quali- 
dade para todas as pessoas, a solução continua distante. (Grifos nossos).

Nessa mesma perspectiva, Caio Paiva e Thimotie Aragon Heeman (2017, p. 627-629) com base na sentença do caso Fazenda Brasil Verde vs. Brasil, nos mostram que o fator econômico das pessoas em situação de escravidão tem um relevo especial:

[...] Afinal, não eram quaisquer pessoas que eram alvo de captação pelos proprietários da Fazenda Brasil Verde, mas sim pessoas com um perfil específico, no qual a pobreza em que viviam era um fator crucial de vulnerabilidade.

Assim, também aliado a esses fatores, a Corte Interamericana identificou que as vítimas estavam em uma situação de vulnerabilidade, uma vez que pairava sobre elas uma situação de pobreza extrema, o que facilitou para que aceitassem as condições que lhes foram impostas pelos proprietários da Fazenda Brasil Verde

No entanto, já se passaram mais de 7 (sete) anos, desde a EC n 81/2014, e até o fechamento desse texto, e nem a Câmara dos Deputados e nem o Senado Federal possuem atualmente minutas legislativas ativas, e muito menos adiantadas, sobre esse tema. Tínhamos o (criticável) Projeto de Lei no 432/2013 do Senado Federal ${ }^{7}$ que restou arquivado no final de 2018. Sobre esse panorama, Lília Carvalho Finelli (2018, p. 64-65) nos traz informações valiosas a respeito daquela EC, desse PL e de parte dessa intricada conjuntura política:

Comemorada a edição da emenda, diversos projetos foram propostos com o objetivo não só de torná-la ineficaz, como também de extirpar de forma indireta duas hipóteses do crime, em especial por meio do PLS no 432/13. Fica clara, assim, a tentativa política de impedir que as condições degradantes e a jornada exaustiva sejam motivo para apreender terras particulares. As discussões entre parlamentares são claras e aptas a indicar que, a bem da verdade, não há necessidade real de regulamentar o dispositivo inserido, que já tem seus procedimentos definidos na lei de expropriação de glebas de cultivo ilegal de plantas psicotrópicas. O que se vê é, em realidade, o desejo de retroceder nas previsões de hipóteses de trabalho escravo, com a desculpa de regulamentar a "nova" forma de confisco de terras.

Assim, até o julho de 2021, há apenas requerimentos para a realização de audiências públicas que datam de 2020 e há um longo hiato de 19 anos, entre a Proposta de Emenda, 1995, e sua aprovação, em 2014, como lembra Herena Neves Maués Corrêa de Melo (2018, p. 231). Nisso a aprovação da Emenda que aparentava ser uma vitória, porém foi opaca e o art. 243 da

7 Disponível em: https://legis.senado.leg.br/sdleg-getter/documento?dm=3773638\&ts=1594020633901\&disposition=inline. Acesso em: 18 de mai. 2021. 
Constituição se tornou, por enquanto, letra morta ${ }^{8}$.

Nesse mesmo fluxo, a lei demorará para sair do papel e não se sabe como sairá. Uma explicação é a atuante frente parlamentar ruralista. Isso, todavia, não é novidade, porquanto sempre existiu, com presença notável nas legislaturas da república, com pautas conservadoras, inclusive no combate à escravidão contemporânea.

Nesse ponto, Leonardo Sakamoto $(2007$, p. 63$)$ realizou um levantamento entre doações para campanhas eleitorais de deputados federais e senadores e a atuação desses parlamentares contra projetos antiescravistas no Congresso. Robson Heleno da Silva e Valena Jacob (2017, p. 34-35) também estiveram atentos ao problema:

Conforme exposto na análise acima, o fortalecimento de uma Bancada Ruralista no Congresso Nacional tem como consequência direta a eclosão de projetos de lei cujas previsões atentam diretamente contra a lógica de combate ao trabalho escravo. Os argumentos utilizados, consoantes restaram demonstrados, não prosperam e ignoram a produção doutrinária dos últimos anos, denotando o apego a concepções coloniais acerca do tema. [...]

Importante destacar ainda que a dita Bancada Ruralista é composta, em sua maioria, por latifundiários e empresários do agronegócio, que reúnem em si poder econômico e político, e voltam sua atuação a temas que lhes favoreçam diretamente, sendo verdadeiros legisladores em causa própria. (Grifos nossos).

De mais a mais, ainda existia uma campanha do presidente da República Jair Bolsonaro para criar obstáculos à aplicação do art. 243 da Constituição.

Em giro próximo, podemos dizer que na exposição de motivos da Proposta de EC do trabalho escravo há a menção expressa à EC n 81/2014, ou seja, a perda da propriedade privada pelo crime da escravidão contemporânea poderia se dar em demanda que tramitaria no judiciário, em vez, de se realizar em instâncias administrativas como futuramente poderia ocorrer, assim, que a norma da Emenda no 81 fosse regulamentada.

A reforma constitucional tinha um objetivo central, inibir o crime com uma penalidade maior. Não obstante, teria sido desvirtuado o art. 243 da Constituição em seu curso legislativo, quando vinculou a efetividade do dispositivo à edição de norma posterior, sem tramitar em paralelo com um projeto de lei que já resolveria o problema da obrigação de termos norma legal ou sem aderir, mesmo que parcialmente, ao texto do art. 149 do CP.

Nesse mérito, Daniela Valle da Rocha Muller (2020, p. 159-160) salienta que, existe no Brasil uma significativa resistência dos operadores judiciais em

8 Movimentos sociais que se mobilizaram pela aprovação da PEC deixaram de pressionar o legislativo para definir a questão, temerosos de que poderia advir um retrocesso ainda maior nessa futura lei que definiria o que é escravidão contemporânea 
consagrar o art. 149 do CP e o substrato anti-escravidão na sua potência devida:

A profunda divergência na compreensão judicial sobre o que é e onde acontece o trabalho escravo nos dias de hoje chama a atenção, entre outros fatores, porque a alteração do art.149 do CPB teve por objetivo declarado superar a imprecisão da sua redação original, considerada vaga e lacônica, e que dificultava sua aplicação prática. Portanto, a princípio, a nova redação legal, intencionalmente descritiva e analítica, não deveria despertar maiores divergências interpretativas, até porque atendia às diretrizes do I PNETE ${ }^{9}$ de estabelecer ferramentas legais para o combate do trabalho escravo contemporâneo.

Com todas essas ideias podemos refletir: Temos um texto constitucional oco? O ideal seria que o Congresso Nacional, de forma ágil, tivesse elaborado um ato normativo par e passo com a reforma da Constituição, detalhando como se daria a perda da propriedade privada, fazendo as inclusões na Lei no 8.257/1991 (lei da expropriação por cultura ilegal de planta psicotrópica) que já possui os instrumentos previstos, com alguns ajustes para observar o devido processo legal, o contraditório e a ampla defesa, como a função social da propriedade? O que não foi feito.

A aprovação da EC já tinha sido algo difícil, e foi obtida com a pressão dos movimentos sociais e outros atores políticos. A aridez, aqui seria por tocar no "sagrado direito" da propriedade?

Sobre isso, boa parte dos aplicadores da lei concorda. Mas há quem considere essa atitude uma visão de um positivismo jurídico, de ocasião, pois, quando interessa, a norma é esquecida e/ou distorcida. Talvez algo pudesse ser ousado e seria uma oportunidade de discutir como essas propriedades privadas se estabeleceram e lucraram a partir de um crime.

Por isso, reforçamos que temos em nossas mãos um problema que é tanto legal, pela sua omissão, quanto pela falta de interesse das pessoas que gerem a máquina judiciária em destravar a agenda e aplicar as leis antiescravistas.

O contexto político de interesses ruralistas não está, como vimos, desconectado de interesses econômicos. Temos um modo de produção em que o engenho colonial não foi abandonado e a marca é a acumulação de capital. Nisso a escravidão contemporânea é um meio para se atingir a mais valia, pois é custoso reduzir os custos de produção dos insumos, tendo em vista a alta competitividade no mercado.

Assim, a escravidão contemporânea possibilitaria a redução dos custos para que o produto final se tornasse mais barato e atrativo para ser negociado, segundo Ilda Pires Galleta (2009, p. 205). O capitalismo mais avançado

9 PNETE - Plano Nacional de Erradicação do Trabalho Escravo. 
e moderno convive com formas arcaicas de produção. Isso se dá nas lonjuras amazônicas ou nas áreas metropolitanas e modernas do Brasil e do exterior. Os envolvidos sabem dos riscos.

No caso brasileiro, sabem que podem ser incluídos na chamada "lista suja" dos escravocratas, ter dificuldades de acesso a créditos bancários, não conseguir participar de licitações públicas, pagar por danos morais individuais e/ ou coletivos. Tem em mente que são poucos os auditores fiscais e buscam se proteger em terceirizações de responsabilidades trabalhistas e criminais.

Nesse fluir, deve imperar uma leitura decolonial, como abona Joaquin Herrera Flores (2006, p 36) mesmo sem estudar diretamente nosso objeto de pesquisa. A verdade é que o proceder escravagista retroalimenta um ciclo destrutivo da sociedade e de pauperismo e "coisificação" da pessoa e sua família que permanecerão nas bordas da cidadania e do usufruto dos direitos humanos.

\section{Considerações finais}

Na escravização a pessoa e os seus perdem muito e por isso podemos invocar David Sánchez Rubio (1999, p 25-27) para que superemos o chamado "efeito encantatório dos direitos humanos" de maneira que a teoria crítica dos direitos humanos produza não só normas internacionais e nacionais elogiáveis, mas que existam políticas públicas que favoreçam a autonomia e a responsabilidade de certos grupos sociais, conferindo-lhe voz, assento e espaço, como as pessoas em situação de escravidão, para que saiam das franjas sociais e acessem os direitos humanos na sua plenitude.

Nesse sentido, devemos suplantar a falácia de que o imaginário colonial de que as ideias dos empresários / empreendedores / proprietários do imóvel são as universais e que essa dominância se dá devido a um contexto econômico hegemônico e com isso a perda da propriedade privada pela escravidão contemporânea seria um prenúncio de socialismo/comunismo.

Por isso não podemos aplicar cegamente esse pensamento conservador, sob pena de continuarmos nesse circuito de elevada desigualdade social e fundiária em que o Brasil se coloca, por isso, é preciso que nos desvinculemos disso e persigamos uma nova humanidade que esteja regrada pela libertação social de todo poder que reproduza pauperismo, exploração e discriminação e ao mesmo tempo, valorizando a reforma agrária e as habitações populares.

Conquanto exista esse panorama negativo, a perda da propriedade privada por uso da escravidão contemporânea faria justiça às pessoas escravizadas que receberiam uma mínima compensação, sendo que a sociedade brasileira ainda receberia de volta um cidadão com possibilidade de usar adequadamente os seus direitos humanos. 
Em compêndio, por essas considerações sociais, culturais, jurídicas, políticas e econômicas a perda da propriedade privada por uso da escravidão contemporânea não só daria maior concretude à reforma agrária e às habitações populares, colocando o Brasil, pelo menos, nesse quesito da escravidão contemporânea, no rumo da quebra do contexto colonial e de opressão das pessoas escravizadas. Em outras palavras, seria um bom intento na emancipação das pessoas em situação de escravidão.

\section{Referências}

BOBBIO, Norberto. A era dos direitos. tradução Carlos Nelson Coutinho; apresentação de Celso Lafer. [Nova ed.] Rio de Janeiro: Elsevier, 2004.

BRASIL. Constituição da República Federativa do Brasil, de 5 de outubro de 1988. Diário Oficial da União. Brasília, DF, 1988. Disponível em: http://www.planalto. gov.br/ccivil_03/constituicao/constituicao.htm. Acesso em: 5 mai. 2021.

BRASIL. Código Penal, de 07 de dezembro de 1940. Diário Oficial da União. Rio de Janeiro, RJ, 1940. Disponível em: http://www.planalto.gov.br/ccivil_03/ decreto-lei/del2848compilado.htm. Acesso em: 7 mai. 2021.

BRASIL. Portaria no 1.129, de 13 de outubro de 2017. Diário Oficial da União. Brasília, DF, 2017. Disponível em: https://www.in.gov.br/materia/-/asset_ publisher/Kujrw0TZC2Mb/content/id/19356195/do1-2017-10-16-portaria-n1-129-de-13-de-outubro-de-2017-19356171. Acesso em: 13 mai. 2021.

BRASIL. Portaria no 1.293, de 28 de dezembro de 2017. Diário Oficial da União. Brasília, DF, 2017. Disponível em: https://www.in.gov.br/materia/-/asset_ publisher/Kujrw0TZC2Mb/content/id/1497798/do1-2017-12-29-portaria-n1-293-de-28-de-dezembro-de-2017-1497794. Acesso em: 13 mai. 2021.

BRASIL. Declaração Universal dos Direitos do Homem de 1948. Diário Oficial da União. Rio de Janeiro, DF, 1945. Disponível em: http://www.planalto.gov.br/ ccivil_03/decreto/1930-1949/d19841.htm. Acesso em: 16 mai. 2021.

BRASIL. Convenção Suplementar sobre a Abolição da Escravatura de 1956. Diário Oficial da União. Brasília, DF, 1966. Disponível em: http://www.planalto.gov. br/ccivil_03/Atos/decretos/1966/D58563.html. Acesso em: 11 mai. 2021. CANOTILHO, José Joaquim Gomes. Direito Constitucional e Teoria da Constituição. Coimbra: Almedina, 1998. 
CASTILHO, Ela Wiecko V. de. Considerações sobre a interpretação jurídico-penal em matéria de escravidão. Estudos Avançados, 2000.

CORTE INTERAMERICANA DE DIREITOS HUMANOS. Caso Fazenda Brasil Verde vs. Brasil. Disponível em: https://www.corteidh.or.cr/docs/casos/articulos/ seriec_318_por.pdf. Acesso em: 16 mai. 2021.

FIGUEIRA, Ricardo Rezende. A persistência da escravidão ilegal no Brasil. Lugar Comum, Rio de Janeiro, n. 33/34, p. 105-121, 2018.

FIGUEIRA, Ricardo Rezende. Liberdade, dignidade e discriminação estrutural: a sentença da Corte Interamericana. In: Trabalho escravo: condenação do Brasil pela Corte Interamericana de Direitos Humanos no caso Brasil Verde. Brasília: CONATRAE, p. 33/26, 2017.

FINELLI, Lília Carvalho. Histórico e interpretação do Artigo 243 da Constituição da República de 1988: expropriação de terras onde for localizada a exploração de trabalho escravo. In: MIRAGLIA, Lívia M. M.; HERNANDEZ, Julianna do N.; OLIVIERA, Rayhanna F. de S. (org.). Trabalho escravo contemporâneo: conceituação, desafios e perspectivas. Rio de Janeiro: Lumen Juris, 2018.

FINELLI, Lília Carvalho. Construção e desconstrução da lei: A arena legislativa e o trabalho escravo. Dissertação (Mestrado em Direito) - Universidade Federal de Minas Gerais, Faculdade de Direito, 2016.

FLORES, Joaquin Herrera. La reinvención de los derechos humanos. Sevilha: Atrapasueños, 2008.

FLORES, Joaquin Herrera. Colonialismo y violencia. Bases para una reflexión pos-colonial desde los derechos humanos. Revista Crítica de Direitos Sociais, Coimbra, n. 75, out., 2006.

GALLETTA, Ilda Pires. Trabalho escravo no Brasil contemporâneo: abordagem histórica e alguns pressupostos teóricos. Revista do Tribunal Regional do Trabalho da 15a Região, Campinas, n. 35, p. 201-208, jul./dez. 2009.

HADDAD, Carlos Henrique Borlido e MIRAGLIA, Lívia Mendes Moreira Miraglia. O Brasil, o trabalho escravo e a corte interamericana de direitos humanos: uma análise dos casos. In: MIRAGLIA, Lívia M. M.; HERNANDEZ, Julianna do 
N.; OLIVIERA, Rayhanna F. de S. (org.). Trabalho escravo contemporâneo: conceituação, desafios e perspectivas. Rio de Janeiro: Lumen Juris, 2018.

MELO, Herena Neves Maués Corrêa de. A ineficácia da Emenda Constitucional $n^{\circ} 81 / 2014$ e a descontração dos fundamentos do trabalho escravo contemporâneo. Revista de Direito Agrário. Goiânia, ano 21, n. 22, 2018.

MIRAGLIA, Lívia Mendes Moreira. Trabalho Escravo Contemporâneo: conceituação à luz do princípio da dignidade da pessoa humana. Dissertação (Mestrado em Direito do Trabalho) - Pontifícia Universidade Católica de Minas Gerais, Belo Horizonte, 2008.

MULLER, Daniela Valle da Rocha. A representação judicial do trabalho análogo ao de escravo. Rio de Janeiro, 2020. Dissertação (Mestrado em Políticas Públicas e Direitos Humanos) - Universidade Federal do Rio de Janeiro, Rio de Janeiro, 2020.

NELSON, Rocco Antonio Rangel Rosso, TEIXEIRA, Walkyria de Oliveira Rocha e NELSON, Isabel Cristina Amaral de Sousa Rosso. Do trabalho em condições análogo ao de escravo um resgate dos direitos sociais por meio da nova portaria $\mathrm{n}^{\circ}$ 1.293/17 do Ministério do Trabalho. Vertentes do Direito, Palmas, v. 5, n. 1. p. 1-21, jun. / 2018.

PAIVA, Caio Cezar; HEEMAN, Thimotie Aragon. Jurisprudência Internacional de Direitos Humanos. 2. ed. Belo Horizonte: Editora CEl, 2017.

RUBIO, David Sánchez. Encantos e desencantos dos direitos humanos: de emancipações, libertações e dominações. Porto Alegre: Livraria do Advogado, 2014.

RUBIO, David Sánchez. Filosofía, derecho y liberación en América Latina. Bilbao: Desclée de Brouwer, 1999.

SAKAMOTO, Leonardo Moretti. Os acionistas da casa-grande: a reinvenção capitalista do trabalho escravo no Brasil contemporâneo. Tese (Doutorado em Ciência Política) - Faculdade de Filosofia, Letras e Ciências Humanas, USP, São Paulo, 2007.

SCOTT, Rebecca. O trabalho escravo contemporâneo e os usos da história. In: ENCONTRO ESCRAVIDÃO E LIBERDADE NO BRASIL MERIDIONAL, 6, 2013, 
Florianópolis. Anais do VI Encontro. Florianópolis: UFSC, 2013.

SENADO FEDERAL. Projeto de Lei $n^{\circ} 432$ do Senado Federal. Disponível em: https://legis.senado.leg.br/sdleg-getter/ documento? $\mathrm{dm}=3773638 \& \mathrm{ts}=1594020633901 \&$ disposition=inline. Acesso em: 18 mai. 2021.

SILVA, Robson Heleno da Silva; VALENA, Jacob. Trabalho escravo o combate em xeque: Uma análise crítica sobre as tentativas de alteração do conceito e seus desdobramentos. Revista de Direito do Trabalho e Meio Ambiente do Trabalho, Brasília, v. 3, n. 1, p. 23/36, jan/jun. 2017.

SUPREMO TRIBUNAL FEDERAL. Inquérito n 3.412/AL. Disponível em: https:// redir.stf.jus.br/paginadorpub/paginador.jsp?docTP=TP\&docID=3076256. Acesso em: 13 mai. 2021.

SUPREMOTRIBUNALFEDERAL. Medida CautelarnaArguiçãode Descumprimento de Preceito Fundamental no 489/DF. Disponível em: http://www.stf.jus.br/ arquivo/cms/noticiaNoticiaStf/anexo/ADPF489liminar.pdf. Acesso em: 13 mai. 2021.

TRINDADE, Daniel de Souza. Conceito de trabalho escravo no Brasil: a necessária aplicação do princípio da proibição do retrocesso social. Trabalho de Conclusão de Curso (Pos-Graduação lato sensu em Direito Legislativo). Instituto Legislativo Brasileiro, Brasília, 2014. Disponível em: https://www2. senado.leg.br/bdsf/bitstream/handle/id/513251/TCC\%20-\%20Daniel\%20 Souza\%20da\%20Trindade.pdf?sequence=1\&isAllowed=y Acesso em: 12 nov. 2021. 